\title{
Study of acceptance of intra caesarean IUCD as method of contraception
}

\author{
Deepti Gupta, Swati Sharma*, Anjali Kanhere, Ishrat Jahan
}

Department of Obstetrics and Gynecology, Chirayu Medical College and Hospital, Bhopal Indore Highway, Near Bairagarh, Bhopal, Madhya Pradesh, India

Received: 13 September 2017

Revised: 26 September 2017

Accepted: 06 October 2017

\section{*Correspondence:}

Dr. Swati Sharma,

E-mail: sharmaswati1976@gmail.com

Copyright: ( ) the author(s), publisher and licensee Medip Academy. This is an open-access article distributed under the terms of the Creative Commons Attribution Non-Commercial License, which permits unrestricted non-commercial use, distribution, and reproduction in any medium, provided the original work is properly cited.

\section{ABSTRACT}

Background: Worldwide around 115 million women have unmet needs of family planning. Increasing rates of institutional deliveries create opportunities for providing quality postpartum family planning services thus helps to overcome the unmet needs. PPIUCD appears an ideal method for limiting and spacing births. The present study was a prospective study, undertaken to assess the efficacy, safety and outcome of Postpartum Intrauterine Contraceptive Device (PPIUCD) in cesarean case.

Methods: A prospective study was done on 50 patients undergoing cesarean section for various indications after getting approval from the Ethical Committee of the institution This study was conducted at CMCH hospital Bhopal, India from August 2016 to July 2017. Women were counseled and those who fulfilled the medical eligibility were provided the PPIUCD services. IUCD was placed after delivery of placenta in case of caesarean section. These clients were followed at 6 weeks, 3 months and 6 months interval.

Results: Total acceptance rate in our study was 44\%. Majority belonged to age group of 21-30 years (76\%) with mean age of 25.5 years, $54 \%$ were para $2,94 \%$ of clients were literate, $86 \%$ urban and only $70 \%$ of the clients were familiar with the intracaesarean IUCD, $54.5 \%$ cases returned for follow-up while $18.2 \%$ of cases were lost to followup and expulsion was the main problem (27.3).

Conclusions: Intracaesarean IUCD seems to be a safe long acting highly effective, easily accessible, reversible and cost effective contraceptive method for most postpartum women specially lactating women.

Keywords: Contraception, Intracesarean IUCD, PPIUCD

\section{INTRODUCTION}

India, with $1,349,664,917$ (1.34 billion) people is the second most populous country in the world, while China is on the top with over $1,415,489,506$ (1.41 billion) people. The figures show that India represents almost $17.85 \%$ of the world's population. (Population of India (2017) (indiaonlinepages.com). ${ }^{1}$

Some of the reasons for India's rapidly growing population are poverty, illiteracy, high fertility rate, rapid decline in death rates or mortality rates and immigration from Bangladesh and Nepal. Alarmed by its swelling population, India started taking measures to stem the growth rate quite early. In fact, India by launching the National Family Planning program in 1952 became the first country in the world to have a population policy.

The family planning program yielded some noticeable results, bringing down significantly the country's fertility rate. In 1965-2009, the contraceptive usage more than tripled and the fertility rate reduced drastically. 
Postpartum period is one of the critical times when both woman and newborn need a special and integrated package of health services as morbidity and mortality rates are quite high during this period and also the women are vulnerable to unintended pregnancy. Studies show that pregnancies taking place within 24 months of a previous birth have a higher risk of adverse outcomes like abortions, premature labor, postpartum hemorrhage, low birth weight babies, fetal loss and maternal death. ${ }^{2-4}$

Women are highly motivated and receptive to accept Family Planning (FP) methods during the postpartum period. $^{5}$ Institutional deliveries have increased significantly all across the country, thereby creating opportunities for providing quality postpartum family planning services. The postpartum services need to be strengthened by integrating maternal and child health $(\mathrm{MCH})$ and FP services at each level of health facility from the district hospital to the sub-centre.

The increased institutional deliveries are the opportunity to provide women easy access to immediate contraceptive as PPIUCD.

The present study was, a prospective study, undertaken to assess the acceptance and safety of intracaesarean Intrauterine Contraceptive Device and to determine the rates of complications (bleeding, pelvic infection, lost strings, and displacement) following intracaesarean Intrauterine Contraceptive Device insertion among the clients with a follow up 6 months.

\section{METHODS}

A prospective study was done on 50 patients undergoing cesarean section for various indications after getting approval from the Ethical Committee of the institution This study was conducted at $\mathrm{CMCH}$ hospital Bhopal, India from August 2016 to July 2017. Women admitted at $\mathrm{CMCH}$ hospital, Bhopal were counseled and those who fulfilled the medical eligibility criteria and had no contra indication for application of intracaesarean Intrauterine Contraceptive Device were provided with the same. ${ }^{2}$

The proforma was prepared in form of questionnaire and with the help of questionnaire required information was collected.

The women presenting to labor room were counseled and invited to participate in the study. IUCD was placed after delivery of placenta in caesarean section. Insertion was done either manually or using a ring forceps as we can easily see and reach the uterine fundus. We hold the IUCD between the middle and index fingers of the hand and pass it through the uterine incision. Once it is placed at the fundus, the hand was slowly withdrawn, noting whether the IUCD remains properly placed.

The strings can be pointed towards the cervix but should NOT be pushed through the cervical canal. This is to prevent uterine infection by contamination of the uterine cavity with vaginal flora, and to prevent displacement of the IUCD from the fundus by drawing the strings downward toward the cervical canal. Care should be taken during closure of the uterine incision that the strings of the IUCD do not get included into the suture.

These clients were followed at 6 weeks, 3 months and 6 months interval for satisfaction, efficacy, safety, effect on menstrual cycle, removal and continuation. ${ }^{2,3}$

\section{Inclusion criteria}

- Women willing for Copper T insertion and its follow up undergoing caesarean section at $\mathrm{CMCH}$ Bhopal.

- Women meeting all the eligibility criteria for Post PartumIUCD. 2,3

\section{Exclusion criteria}

Women having

- Chorioamnionitis or Puerperal sepsis.

- Prolonged rupture of membranes of $>18 \mathrm{hrs}$

- Extensive genital trauma.

- Unresolved PPH

- Any abnormality of uterus or a large Fibroid distorting its cavity

- Pelvic inflammatory disease

- Malignant or benign trophoblastic disease $h$. HIV/AIDS.

\section{RESULTS}

A total of 50 women were counselled and motivated for intracaesarean Intrauterine Contraceptive Device adoption. Out of this, 22 women accepted the method. Total acceptance rate was $44 \%$.

Table 1: Distribution of age.

\begin{tabular}{|lll|}
\hline Age in years & Number & $\%$ \\
\hline$\leq 20$ & 6 & 12 \\
\hline $21-30$ & 38 & 76 \\
\hline $31-40$ & 6 & 12 \\
\hline Total & 50 & 100 \\
\hline
\end{tabular}

Majority of cases were between the age group of 21-30 years $(76 \%)$ which includes reproductive age group and are more receptive to contraceptive counselling.

Table 2: Parity.

\begin{tabular}{|l|l|l|}
\hline & Number & $\%$ \\
\hline P1 & 17 & 34 \\
\hline P2 & 27 & 54 \\
\hline P3 & 6 & 12 \\
\hline Total & 50 & 100 \\
\hline
\end{tabular}


Table 2-4 shows the demographic characteristics of the PPIUCD clients. Most of the clients were para-2 (54\%), $17 \%$ were Parity 1 and 6\% were Parity 3.

Table 3: Education.

\begin{tabular}{|lll|}
\hline & Number & $\%$ \\
\hline Illetrate & 3 & 6 \\
\hline Primary & 5 & 10 \\
\hline Secondary & 14 & 28 \\
\hline Graduate & 22 & 44 \\
\hline Post graduate & 6 & 12 \\
\hline Total & 50 & 100 \\
\hline
\end{tabular}

Table 3 shows $94 \%$ of our patients were literate with $22 \%$ graduate and $14 \%$ had attained secondary education which also reflects improving literacy status of the society and indicating that education is an important factor in awareness and acceptance of intracaesarean IUCD.

Education renders people more receptive to new ideas and practices, spacing methods, and importance of small family norms. Education is also a major factor in fertility control.

Table 4: Residence.

\begin{tabular}{|lll|}
\hline & Number & $\%$ \\
\hline Rural & 7 & 14 \\
\hline urban & 43 & 86 \\
\hline Total & 50 & 100 \\
\hline
\end{tabular}

Table 4 shows, majority of cases in present study were residents of urban areas ( $86 \%$ ) as our hospital is a tertiary care centre and caters majorly urban population.

Table 5: Awareness of method.

\begin{tabular}{|lll|}
\hline & Number & $\%$ \\
\hline Yes & 35 & 70 \\
\hline No & 15 & 30 \\
\hline Total & 50 & 100 \\
\hline
\end{tabular}

Table 5 shows, though majority of the women were aware of copper-T (70\%) but few had ever heard of insertion in the postpartum period (PPIUCD). Awareness about PPIUCD needs to be increased at grass root level (aaganwadi workers, PHC'S) to increase success of contraceptive methods.

Table 6: Return to follow up.

\begin{tabular}{|lll|}
\hline Lost to follow up & Number & $\%$ \\
\hline Regular follow up & 4 & 18.2 \\
\hline Follow up on phone & 12 & 54.5 \\
\hline Erratic follow up & 2 & 9.1 \\
\hline Total & 4 & 18.2 \\
\hline
\end{tabular}

Table 6 shows, 4 cases were lost to follow up during the study. Of the 18.4 came for erratic follow up, 2 were followed telephonically and 12 came for regular follow up. The patients need to be counselled about proper follow up to reduce complications and failure of this contraceptive method.

Table 7: Complaints at follow up.

\begin{tabular}{|lll|}
\hline Complaints & Number & $\%$ \\
\hline Pain & 2 & 9.1 \\
\hline Abnormal uterine bleeding & 2 & 9.1 \\
\hline Abnormal vaginal discharge & 0 & - \\
\hline Decreased lactation & 0 & - \\
\hline Spontaneous expulsion & 6 & 27.3 \\
\hline Perforation & 0 & - \\
\hline Missing thread & 3 & 13.6 \\
\hline No complaints & 9 & 40.9 \\
\hline Total & 22 & 100 \\
\hline
\end{tabular}

Table 7 shows, post-placental IUCD recipients expulsion was the main problem $(27.3 \%)$. No case of perforation or any other major complication was found. PPIUCD also had no effect on lactation. Only 2 patients reported pain on follow up which was relieved with analgesics and 2 patients reported abnormal uterine bleeding as polymenorrhagia which was relieved by oral contraceptives for few cycles.

\section{DISCUSSION}

Intracaesarean Intrauterine Contraceptive Device seems to be a safe long acting highly effective, easily accessible, reversible and cost effective contraceptive method for most postpartum women specially lactating women. Total acceptance rate in our study was $44 \%$. Total acceptance rate of PPIUCD in Gupta A et al study was $14.4 \%$ and in study by Kanhere et al acceptance rate was $36 \%$. $^{5,6}$

Majority belonged to age group of 21-30 years (76\%)with mean age of $25.5 y e a r s$. This was probably because they considered PPIUCD as an effective spacing method. In study of Upmanyu et al average age of PPIUCD acceptance was 28.3 years. ${ }^{7}$

The results of present study showed that $54 \%$ of total intracaesarean Intrauterine Contraceptive Device acceptors were having 2 children, as they wanted some form of contraception awaiting permanent sterilization. In study of Katheit et al $34.7 \%$ of PPIUCD acceptors were para $2 .^{8}$

During this study, it is seen that $94 \%$ of clients were literate indicating that education is an important factor in awareness and acceptance of intracaesarean IUCD. Education renders people more receptive to new ideas and practices, spacing methods, and importance of small family norms. Education is also a major factor in fertility control. In study of Katheit et al $65 \%$ of PPIUCD acceptors were educated clients. ${ }^{8}$ 
We found in present study that the acceptance of intracaesarean IUCD was higher in urban (86\%) women. Though women of urban areas have easy access to other methods of contraception like condoms, permanent sterilization they still prefer intracaesarean IUCD because of its various benefits like free of side effects, free of cost availability, reversibility.

It was also evident from the study that proper guidance, information and motivation lead to high acceptance of intracaesarean IUCD among rural women. This clearly indicates that training to ASHA, ANMs and anganwadi workers and integrating this method in national programmes like National rural health mission could contribute significantly in family planning programme. In study of Katheit et al residence was not a significant factor in acceptance of PPIUCD and in Revising unmet need for family planning DHS Analytical studies No. 25 by Bradley et al shows substantially higher levels of unmet need in rural than in urban areas. ${ }^{5,9}$

During the study it was found that only $70 \%$ of the clients were familiar with the intracaesarean IUCD, whereas awareness was $73.5 \%$ in study of Katheit et al. ${ }^{8}$ Although women who knew about PPIUCD had many misconceptions and myths about it like it affects lactation, non reversible method, cause pain and heavy bleeding, hinders during coitus etc. During the study these misconceptions were cleared up and women were educated, counselled and motivated about IUCD along with providing PPIUCD insertions.

In present study, $54.5 \%$ cases returned for follow-up while $18.2 \%$ of cases were lost to follow-up. The women who did not return for follow up were mostly from far off rural areas. Lack of family support, non-availability of transport facility could be the reason for non-compliance. In study of Katheit et al, $83.4 \%$ cases returned for followup while $16.12 \%$ of cases were lost to followup. ${ }^{8}$

In present study, intracaesarean IUCD recipients' expulsion was the main problem $(27.3 \%)$. No case of perforation or any other major complication was found. Intracaesarean IUCD also had no effect on lactation. The expulsion after intracaesarean insertion occurred in $2 \%$ case in study of Gupta $A$ et al and $10.5 \%$ in study of Katheit et al. ${ }^{5,8,10,11}$

\section{CONCLUSION}

Intracaesarean IUCD seems to be a safe long acting highly effective, easily accessible, reversible and cost effective contraceptive method for most postpartum women specially lactating women. Despite the potentially higher expulsion rate for PPIUCDs, the public health benefit of the service must be considered.

The importance of health care providers at grass root level is must to improve acceptance rate of intracaesarean IUCD as most important cause of non acceptance was myths about its complications (bleeding, infections, perforations etc).

The motivation and counseling of family members is also required to improve post insertion follow ups. According to ACOG, IUDs and the contraceptive implant are the best reversible methods for preventing unintended pregnancy, rapid repeat pregnancy, and abortion in young women.

\section{ACKNOWLEDGMENTS}

Authors would like to thank Department of Obstetrics and Gynecology, CMCH Medical College, Bhopal, M.P., for providing CuT 380A/CuT375 devices free of cost. $\mathrm{We}$ are also thankful to all our clients for their cooperation.

\section{Funding: No funding sources \\ Conflict of interest: None declared}

Ethical approval: The study was approved by the Institutional Ethics Committee

\section{REFERENCES}

1. Population of India. 2017. Available at http://www.indiaonlinepages.com/population/indiacurrent-population.html

2. Post partum IUCD refrence manual. Family Planning Division, Ministry of Health and Family Welfare, Govt. of India, Chapter1-9. 2010:1-37. Available at http://www.nrhmtn.gov.in/modules/PPIUCD\%20Ref erence\%20Manual.pdf

3. IUCD Reference Manual for Medical Officers, Family Planning Division, Ministry of Health and Family Welfare, Govt of India, July 2007; Chapter1Introduction.1-20.

4. Salem R. New attention to IUD: Expanding women's contraceptive option to meet their needs: Population report: Series B No.7, John Hopkins Boomberg school for public health, The INFO project, Baltimore. 2006;7:1-26.

5. Gupta A, Verma A, Chauhan J. Evaluation of PPIUCD versus interval IUCD (380A) insertion in a teaching hospital of Western U. P. Int J Reprod Contracept Obstet Gynecol. 2013 Jun;2(2):204-8.

6. Kanhere AV, Pateriya P, Jain M. Acceptability and feasibility of immediate postpartum IUCD insertion in a tertiary care centre in Central India. Int J Reprod Contracept Obstet Gynecol. 2015;4(1):179-184.

7. Upmanyu P, Kanhere A. Acceptance of methods of family planning in patients undergoing repeat cesarean section. Int $\mathbf{J}$ Reprod Contracept Obstet Gynecol. 2016;5(4):976-9.

8. Katheit G, Agarwal J. Evaluation of post-placental intrauterine device (PPIUCD) in terms of awareness, acceptance, and expulsion in a tertiary care centre. Int J Reprod Contracept Obstet Gynecol. 2013;2:539-43. 
9. Bradley S, Croft TN, Fishel JD, Westoff CF. Revising unmet need for family planning. DHS Analytical studies No. 25 Calverton (Md): ICF International;2012.

10. American College of Obstetricians and Gynecologists. Adolescents and long acting reversible contraception: implants and intrauterine devices. ACOG. 2012;539.
11. ACOG. Clinical challenges of long-acting reversible contraceptive methods. Committee Opinion No. 672. Obstet Gynecol 2016;128:e69-77.

Cite this article as: Gupta D, Sharma S, Kanhere A, Jahan I. Study of acceptance of intra caesarean IUCD as method of contraception. Int J Reprod Contracept Obstet Gynecol 2017;6:5033-7. 